\title{
Autoria de conteúdos multimídia como atividade de estímulo à descoberta de experiências femininas em TI
}

\author{
Sheyla Medeiros ${ }^{1}$, Thaíse $\operatorname{Costa}^{1}$, Vanessa Dantas ${ }^{1}$, Renata Figueiredo ${ }^{1}$, Beatriz \\ Martins ${ }^{1}$ \\ ${ }^{1}$ Departamento de Ciências Exatas - Centro de Ciências Aplicadas e Educação - \\ Universidade Federal da Paraíba - Campus IV - Rio Tinto - PB - Brasil \\ \{sheyla, thaise, vanessa, renata, beatriz.pamela\}@dce.ufpb.br
}

\begin{abstract}
Multimedia content authoring can be used to promote knowledge, discussion and dissemination of women's experiences in the area of Information Technology (IT). This article presents an experience report about the use of multimedia content authoring to debate the theme among students. The experience provided a reflection on the role of women in IT, supporting to career, and the production of media to show the subject.
\end{abstract}

Resumo. A autoria de conteúdo multimídia pode ser explorada como atividade de incentivo ao conhecimento, discussão e divulgação de experiências femininas na área de Tecnologia da Informação (TI). Este artigo apresenta um relato de experiência acerca do uso de criação de conteúdo multimídia como forma de promover e debater a temática entre estudantes. A experiência proporcionou reflexão sobre o papel da mulher na área de TI, ajudando no incentivo à carreira, além da disponibilização do material produzido como meio de divulgação do tema.

\section{Introdução}

A autoria de mídias e produtos multimídia envolve muitos desafios. A superação desses desafios na construção de aplicações ou títulos multimídia deve conduzir a um resultado significativo tanto para o usuário quanto para o autor do produto. À medida que as aplicações são produzidas, considerando as várias etapas do processo de criação, o autor não se especializa apenas na parte técnica do processo, ou seja, nas ferramentas/linguagens, mas também se envolve com o conteúdo que é foco da aplicação. Assim, a autoria pode ser vista como um meio de apoio ao processo de aprendizado, pois à medida que o aprendiz é desafiado a se colocar na posição de desenvolvedor de produto multimídia, ele necessita por em prática técnicas e se aprofundar em conteúdos para a elaboração da aplicação.

O processo de desenvolvimento das mídias que irão constituir uma aplicação é denominada de autoria de conteúdo multimídia [Ribeiro 2015]. Este processo estimula o potencial inventivo dos discentes, favorecendo a curiosidade e pensamento crítico. Em um processo de criação de mídias, o aluno precisa explorar em maior profundidade a temática, a fim de construir um tipo de mídia significativa. $O$ atual trabalho explora $o$ processo de autoria de conteúdo multimídia associado à temática de gênero, na área de TI (Tecnologia da Informação), buscando incentivar conhecimento, discussão e divulgação de experiências femininas nessa área. 
É importante que as alunas conheçam o papel histórico das mulheres na Computação e o impacto de suas contribuições, a fim de se sentirem valorizadas e estimuladas a desenvolver seus potenciais [Figueiredo et al. 2016]. Oferecer oportunidade de conhecerem feitos na computação que tenham mulheres como principais agentes, pode inspirar e mostrar que há mulheres em destaque na área. Como exemplos históricos, pode-se citar Ada Lovelace, que foi a primeira pessoa a programar; bem como as programadoras da equipe do primeiro computador eletrônico, sendo elas, Kathleen McNulty Mauchly Antonelli, Jean Jennings Bartik, Frances Snyder Holberton, Marlyn Wescoff Meltzer, Frances Bilas Spence e Ruth Lichterman Teitelbaum [PetSi 2016].

No sentido de oferecer oportunidade para que alunos conheçam mulheres inspiradoras na área de TI, o artigo apresenta o esforço para promoção e debate da temática a partir de projetos disciplinares, relatando a experiência obtida com um projeto de autoria de conteúdo multimídia, no escopo da disciplina de Sistemas Multimídia do curso de Licenciatura em Ciência da Computação (LCC), Campus IV, Universidade Federal da Paraíba. A partir dessa iniciativa, alunas e alunos puderam pesquisar, conhecer e disseminar iniciativas de mulheres na área de TI por meio de suas próprias produções.

\section{Materiais e Métodos}

Esta seção explana as estratégias metodológicas aplicadas na disciplina de Sistemas Multimídia no curso de LCC. Explora o processo de autoria de conteúdo multimídia associado à temática de gênero na área de TI, buscando incentivar o aprofundamento na discussão e divulgação de experiências femininas na área.

A experiência foi aplicada com alunos do quinto período do curso, que foram organizados em 4 grupos de 4-5 alunos. Cada grupo foi orientado a construir um infográfico e uma animação, considerando as diretrizes acerca da utilização de conteúdo multimídia. $\mathrm{O}$ processo de autoria foi feito em torno das seguintes temáticas: linha do tempo de mulheres inspiradoras em TI; engajamento e empoderamento feminino na tecnologia; sexismo em TI; e aplicações criadas por mulheres e para mulheres. Seguindo o pensamento de González (2000), buscou-se incentivar a construção de um espaço de informação funcional, concebido de forma a reduzir a sobrecarga cognitiva imposta ao usuário.

Os passos para o desenvolvimento foram quatro:

- Análise: composto pelas atividades de descrição do produto; caracterização do produto enquanto uma aplicação multimídia; público alvo (usuários potenciais); brainstorming; análise de produtos similares; e mapa mental.

- Concepção: com a elaboração de um roteiro para a animação a ser desenvolvida; e prototipagem com a estrutura de navegação.

- Produção: elencando as tecnologias e ferramentas utilizadas no desenvolvimento da aplicação; criação dos conteúdos de textos e imagens (Qual a resolução espacial das imagens? Quais cores serão utilizadas? Quais as dimensões das imagens? Qual o formato das imagens? Quais são bitmap e quais são vetoriais?); conteúdo de vídeo 
(Qual a resolução do filme? Como será capturado? Qual o formato? Quanto tempo de duração?); conteúdo de animação e conteúdo de áudio.

- Teste: testes realizados pelos desenvolvedores e testes realizados junto com usuários (no caso, uma equipe testa o de outra equipe).

\section{Resultados Observados}

Os grupos criaram uma pasta compartilhada, na qual eram inseridos artefatos que seguiam a ordem do processo de desenvolvimento.

\subsection{Análise}

Os grupos estudaram de maneira aprofundada o tema, pensaram no público alvo e buscaram outras aplicações multimídia disponíveis para fazer uma avaliação. A partir dela, refletiram acerca das melhores práticas para a construção do seu próprio infográfico. Esse apanhado fez com que debates acerca de gênero fossem criados em sala de aula. Após o encerramento do processo de análise, cada grupo fez uma apresentação para a turma e discutiram sobre o papel da mulher na TI, ultrapassando os moldes da técnica de ferramentas e aplicações de TI.

\subsection{Concepção}

Com base na pesquisa e definições feitas na $1^{\text {a }}$ fase, os grupos criaram um roteiro para uma animação que tinha caráter ilustrativo e informacional sobre o tema, juntamente com um storyboard, como mostrado na Figura 1.

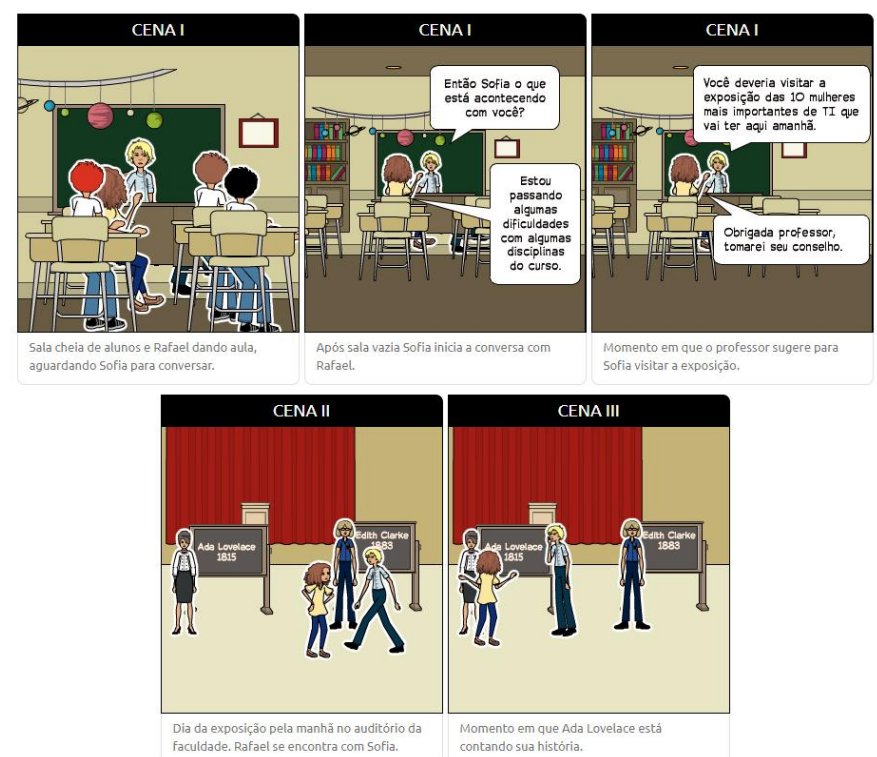

Figura 1. Storyboard da animação do trabalho "Linha no tempo de mulheres inspiradoras na área de Tl”.

\subsection{Produção}

O infográfico foi produzido utilizando tecnologias web, HTML (HyperText Markup Language), CSS (Cascading Style Sheets), JavaScript e JQuery (biblioteca para JavaScript). Ele foi planejado para se adequar às diversas resoluções de dispositivos, utilizando a técnica de design responsivo. Em relação à mídia texto, os caracteres estão formatados em Unicode, UTF-8. Todas as cores utilizadas nos textos do infográfico 
estão no formato RGB (Red, Green, Blue). Os áudios digitais utilizados na narração do texto informativo estão no formato .mp3. A estrutura de navegação foi feita através de rolagem vertical, links acessados por meio de imagens como apresentado na Figura 2.

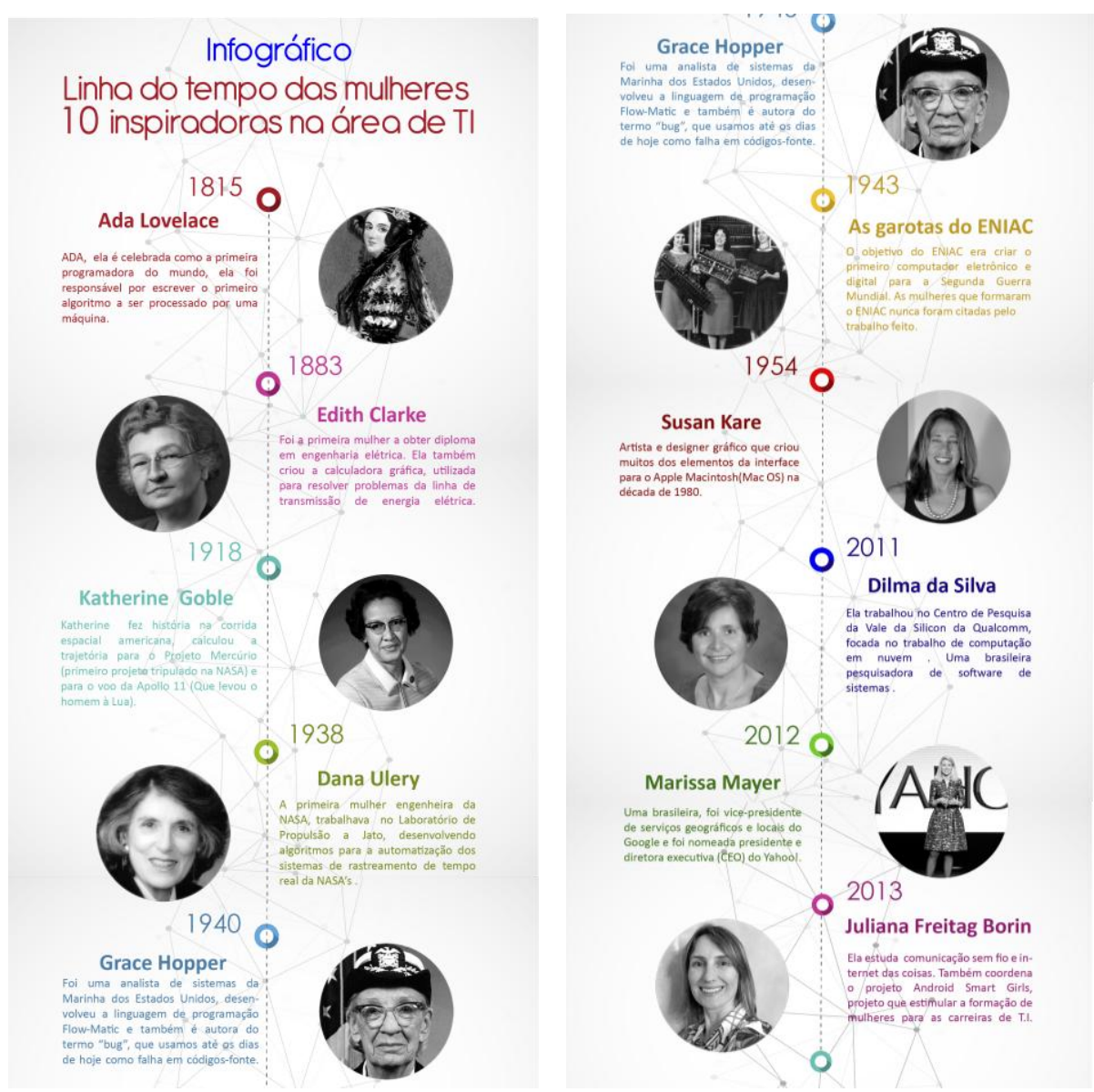

Figura 2. Infográfico do trabalho "Linha no tempo de mulheres inspiradoras na área de Tl'.

\subsection{Teste}

Os testes foram feitos tanto pelos próprios desenvolvedores, quanto pelas outras equipes, obedecendo a um rodízio e seguindo um guia para observação dos roteiros previamente desenvolvidos. Muitos ajustes foram feitos após as observações, principalmente acerca da navegação.

\section{Reflexões sobre a experiência}

Ao longo de todas as etapas, questionamentos sobre gênero foram elucidados e discutidos em sala de aula. As alunas puderam se posicionar de maneira ativa sobre as reflexões do tema e os alunos ouviram e fizeram suas considerações em relação ao papel da mulher na área de TI e incentivo à carreira, promovendo um debate rico e 
proveitoso. Além desse debate interno, o projeto foi capaz de estender essas reflexões para o público externo, através do acesso aos infográficos e animações, tais recursos podem ser utilizados como materiais de apoio para conhecimento, discussão e divulgação das experiências femininas na área de TI.

Este relato de experiência aborda como a autoria de conteúdo multimídia pode ser explorada como atividade de incentivo ao conhecimento, discussão e divulgação de experiências femininas na área de TI, no contexto de disciplinas em um curso de LCC. A experiência traz como contribuições para as alunas a reflexão sobre o papel da mulher na área de TI e incentivo à carreira. Além de possibilitar e incentivar a disponibilização de diferentes mídias de apoio ao conhecimento, discussão e divulgação de experiências femininas que podem ser utilizadas de forma individual ou para compor novos aplicativos ou títulos multimídia que envolvam a temática.

\section{Considerações}

É importante destacar que a experiência em tratar temas relacionados às questões de gênero em Tecnologia de Informação pode ser abordada de diferentes formas, no contexto de diversas disciplinas ou fora delas. Como continuidade ao trabalho de promoção e apoio às mulheres na área de $\mathrm{TI}$, outras atividades vêm sendo desenvolvidas em contextos extracurriculares, como salas de debate com base em filmes, encontros temáticos com intuito de reunir meninas do curso para intercâmbio de experiências, eventos em parceria com outras instituições, ofertas de cursos de capacitação, dentre outros. Atualmente, a divulgação e alguns resultados dessas atividades podem ser acessados em <http:/itgirls.dcx.ufpb.br/>. Acredita-se que a divulgação dessa e outras experiências incentivam os docentes e alunos a disponibilizarem e buscarem espaços para a promoção da temática.

\section{Referências}

Figueiredo, R.V., Dantas, V.F., Coutinho, G., Nascimento, R.R.S., Nascimento, A.C.C., Nunes, B.P.M. (2016) "Um Estudo Inicial Sobre As Alunas Ingressantes no Curso de Licenciatura em Ciência da Computação da Universidade Federal da Paraíba". In: Congresso da Sociedade Brasileira de Computação (CSBC) - Women in Information Technology. Anais do CSBC 2016. Porto Alegre: SBC.

González, M. N. (2000) "O caráter seletivo das ações de informação". Informare, Rio de Janeiro, v. 5, n. 2, p. 7-31.

PetSI (2016) "Mulheres na Computação". O jornal informativo do grupo PET-SI. Disponível em:< http://www.each.usp.br/petsi/jornal/?p=1701>. Acesso em: $19 \mathrm{de}$ mar. de 2018.

Ribeiro, N. (2015) "Multimédia e tecnologias interativas". Lisboa: FCA. 5a edição. $628 \mathrm{p}$. 